\title{
Impact of primary sedimentation tank on wastewater treatment plant units using computer simulation program
}

\author{
Ahmed M. Hussein ${ }^{1}$, Dhiaa Neama Jabbar ${ }^{2}$, Shereen Qasim Abdulridha ${ }^{3}$ \\ Civil Techniques Department, Babylon Technical Institute, Al-Furat Al-Awsat Technical University, Iraq \\ Iamh.eng85@gmail.com,inb.ahd@atu.edu.iq \\ 22dhiaanj@yahoo.com,inb.dya@atu.edu.iq \\ 3. Shereenqasim82@gmail.com,inb.sh.qasim@atu.edu.iq
}

\begin{abstract}
This study presents a computer program designed in Visual Basic 6 program. The capability of this program is to design wastewater treatment plant units and determination of its construction cost.
\end{abstract}

The program deals with two types of wasted sludge the first type is wasted sludge from the aeration basin, while the second system is wasted sludge from the secondary clarifier. Also, there is a detailed output shows the design flowrate, mass balance analysis and composition of each stream in and out of each treatment unit. Program results are verified with hand calculations within the allowable recommended values and they showed a good accuracy.

The volume of aeration basin and secondary sedimentation tank increased with the elimination of primary sedimentation tank from the design of the wastewater treatment plant. Generally, an increment of about $(52-170) \%$ for aeration basins and $(58-185) \%$ for secondary sedimentation tanks are observed in the present study. From other hand, gravity thickener volume is decreased by $(29-42) \%$, anaerobic digester volume is decreased about (38 - 52) \% and drying beds is decreased by $(29-38) \%$ approximately.

The cost analysis showed that the cost of a wastewater treatment plant is increased after a certain amount of influent. That amount is nearly $(36,708.33) \mathrm{m}^{3} / \mathrm{d}$ when wasted sludge is taken from aeration basin and $(24,833.33) \mathrm{m} 3 / \mathrm{d}$ when wasted sludge is taken from secondary clarifier.

Keywords: Sedimentation tank, Wastewatertreatment, DOI : doi.org/10.46617/icbe6003

\section{Introduction}

The purpose of wastewater treatment is to prepare controlled conditions with comparatively small size to remove suspended and soluble materials, treatment biodegradable organics and elimination of pathogenic organisms [1]. Wastewater treatment plant contains various interacting unit processes. The design, operation, and control of these plants are not a simple task [2]. The control of the treatment process is very complex, because of the large number of variables that can affect it [3].

The primary sedimentation tank has great effect on the biological treatment, because, it has considerable roll on removing a great deal of BOD and TSS, in other words, the sedimentation tank facility reduces the organic load that will be processed in the biological unit earlier[4]. Many studies have been done to evaluate the effects of environmental factors on the performance of biological wastewater treatment plants :

AL- Turaihy, T.A, 1993 studied the factors affecting the choice of sewage treatment methods[5]; While Ujang, Z.andSairan, F.2006 designed a computer program in that field.[6] Also E. C. C. F., 2005 made studies on optimal design of wastewater treatment plant [7]; Xiaoyi Z., 2005used Poisson rectangular pulse model toestimate peaking factors[8]. There are also researches done by Arcadio P. S. S., 2003 to find the differences between chemical and physical treatments.[9]Donald. L. B.et. al., 2004 showed how domestic wastewater treatment is affected by many environmental factors.[10], Also Nikoletta K. and DespoF., 2004 showed how urban wastewater treatment is greatly changed by changing the environmental factors.[11] 


\section{Objective of the present paper are:}

The main objectives of this study can be stated as:

1. Building a computer program that will design a wastewater treatment plant with completely mixed activated sludge method by using Visual Basic 6.0 software.

2. Making the program capable of doing the design job for a wastewater treatment plant with two options; the first is with primary sedimentation tank facility while the second option is without the primary sedimentation tank.

3. Discussing the results that will be revealed from these designs.

A typical wastewater treatment plant is accomplished by general steps which are shown in figure (1)[12]

\section{Computer Program Construction}

The program is designed to calculatewastewater treatment plant unitsdimensions. the program will focus on the design of the facilities that follows preliminary treatment, i.e., primary treatment, secondary treatment and sludge treatment facilities in two cases, the first case is the design of the treatment plant in presence of sedimentation tanks. While the second case is the design in absence of sedimentation tanks. Data that was used for design were obtained between minimum and maximum standard values used for design. [13][14][15]

The analysis of the two cases is based upon the analysis of cost as well as performance of the plant.A brief sample of the program forms is shown in Figure (2)

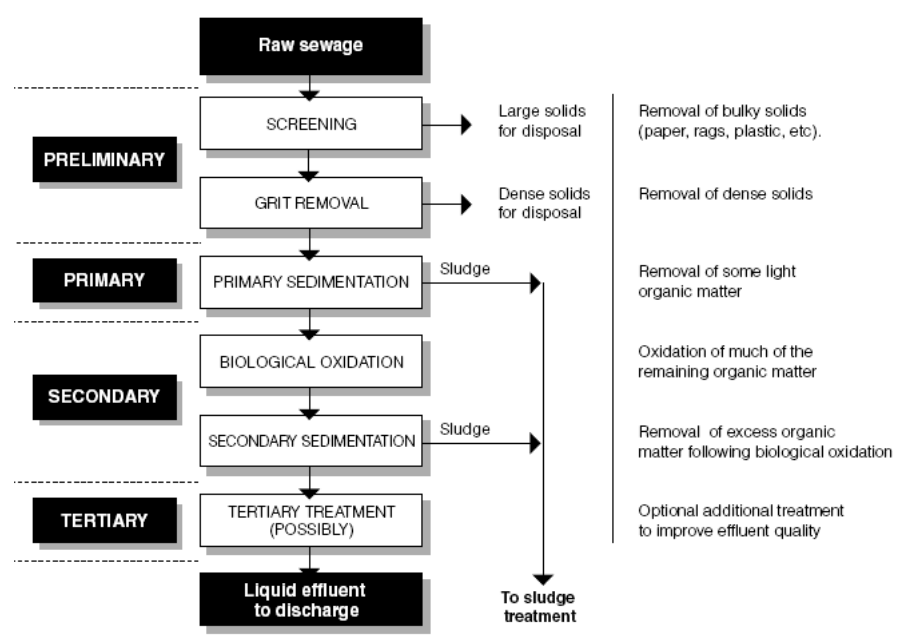

Figure (1) Typical Wastewater Treatment Plant Unit

\section{Verification of Computer Program Results}

It is necessary to check program results before depending on results in the final design of wastewater treatment plant.

Usually, any check is done by comparing the results that have been taken from the program with a standard formulas or equations, in the absence of such equations the program is to be checked with data that has been determined by hand calculation. 


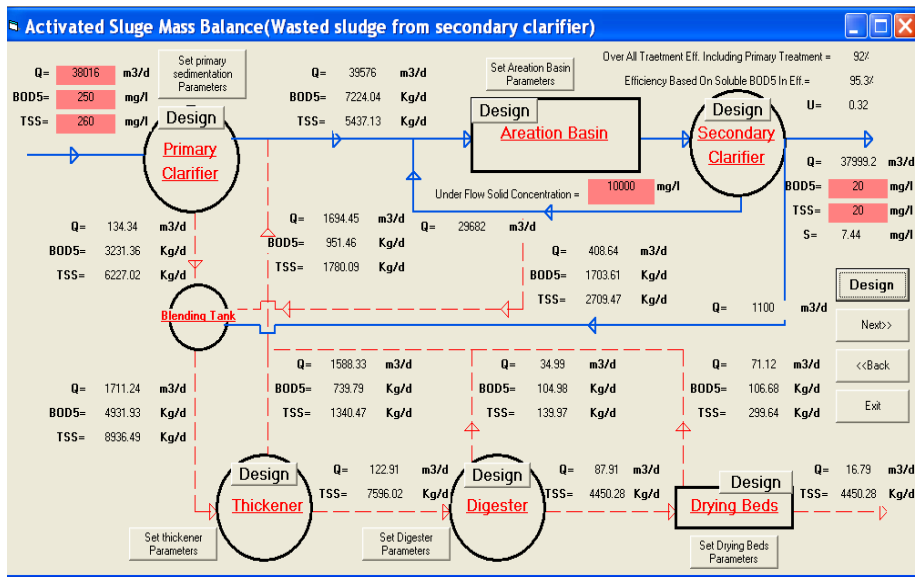

Figure (2) Wasted sludge from secondary clarifier mass balance window

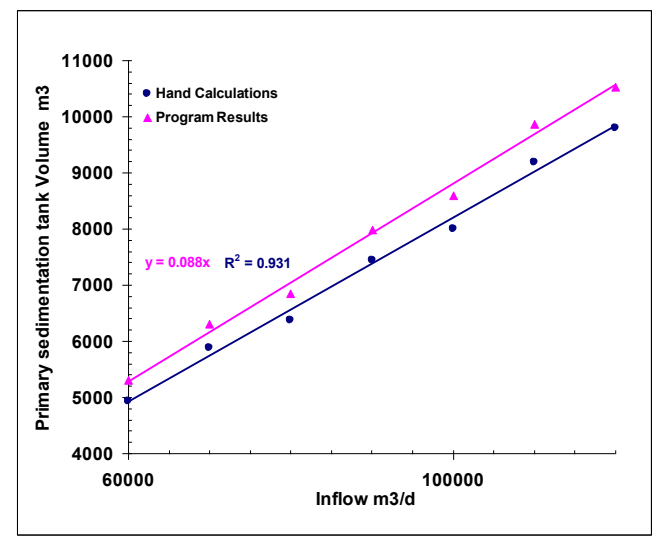

Figure (3) Verification between Hand Calculations and Program Results for Primary Sedimentation Tank Volume

The results obtained from verification are accepted as the program results show good convergence with that obtained by with hand calculation and a sample is shown inFigure (3)

\section{Analysis of Data and Results}

\subsection{DATA}

The flow rates and its characteristics used in the present study to obtain the data used in analysis are show in table (1). [13][14][15]. Additional two inflows $(2500,5000) \mathrm{m} / \mathrm{s}$ was taken to enhance the regression analysis. The wastewater treatment plant units was designed for each of the mentioned (22) influents and this design was repeated (6) times, each time with different TSS and BOD ranging from (150)mg/l to (400)mg/l.

Table (1) Values of Characteristics of Sewage as used inthe program in the present study

\begin{tabular}{|l|l|l|l|l|}
\hline \multirow{2}{*}{ Item } & \multirow{2}{*}{ Units } & Limits & Upper & Increment \\
\cline { 3 - 5 } & & Lower & 200000 & 10000 \\
\hline Influent Flow Rate & $\mathrm{m}^{3} / \mathrm{d}$ & 10000 & 400 & 50 \\
\hline TSS In Influent & $\mathrm{mg} / \mathrm{l}$ & 150 & 400 & 50 \\
\hline BOD5 In Influent & $\mathrm{mg} / \mathrm{l}$ & 150 & & \\
\hline
\end{tabular}




\subsection{Analysis}

Multiple regression analysis were used in this study.In the present work, the volume of each treatment units is assumed to be the dependent variables (y) and the independent variables will be the influent to the wastewater treatment plant. Cost analysis was performed also for the designed plant. The construction costs of each unit for activated sludge treatment plant used in the present study are shown in Table(2). Single regression models in five forms are used for each one of design requirements to investigate which form gives the best fitting of data Table (3) shows these regression models.

Table (2) : Cost of Wastewater Treatment Plant units

\begin{tabular}{|l|l|}
\hline Unit & Cost \% \\
\hline Inlet Pumping Station & 6.75 \\
\hline Screening, Grit Removal and flow measurement & 7.90 \\
\hline Primary Settlement & 6.04 \\
\hline Biological Treatment & 7.90 \\
\hline Final Settlement & 6.22 \\
\hline Chlorination Plant & 2.13 \\
\hline Sludge Treatment Plant & 30.92 \\
\hline Recirculation or Sludge Return Pumps & 1.33 \\
\hline Sludge Pumping Station & 1.77 \\
\hline Electrical Works & 5.34 \\
\hline Administration Block & 2.33 \\
\hline Miscellaneous, Pipe work, Chambers, etc. & 12.14 \\
\hline General Site Works, Roads, etc. & 9.25 \\
\hline Total & 100 \\
\hline
\end{tabular}

\subsection{Results}

Single regression analysis is made to 22 models to find the relationship between independent variables (the influent flow rates, $\mathrm{BOD}_{5}$ and TSS) and dependent variables (volume of each treatment unit) considering presence and absence of primary sedimentation tanks with different values of $\mathrm{TSS}_{\text {inf }}$ and $\mathrm{BOD}_{5 \mathrm{inf}}$. Relationships between the influent and volume of each unit are found using (Microsoft Excel 2019) program for statistical calculations which showed a good degree of accuracy

Table (3): The Proposed Models in the Present Study

\begin{tabular}{|c|c|c|}
\hline No. & Equation & Description \\
\hline $\bar{A}$ & $\nabla a_{2}$ & Linear \\
\hline B & ${ }_{1} \ln (\quad) \otimes a_{2}$ & logarithmic \\
\hline $\mathrm{C}$ & $2^{2}{ }^{2} \quad x^{3} \quad \ldots . .{ }_{k} X^{n}$ & Polynomial \\
\hline $\mathrm{D}$ & $\bigotimes_{1} X^{a_{2}}$ & Power \\
\hline $\mathrm{E}$ & $\nabla_{1} e^{{ }^{2} X}{ }_{1}$ & Exponential \\
\hline
\end{tabular}




\subsubsection{Volume of primary sedimentation tank}

Model No. A was found to be the most suitable model for determining the volume of primary sedimentation tank. The predicted model can be written as:

$$
y \otimes 0.0874 \mathrm{X}
$$

Where;

$y=$ dependent variables, $X=$ the independent variable, $a_{1}, a_{2}, a_{3}, \ldots a_{k}=$ are model coefficients

$n=$ number refers to the polynomial degree

Figure (4) shows the primary sedimentation tank data fit model and its $\mathrm{R}^{2}$ value.

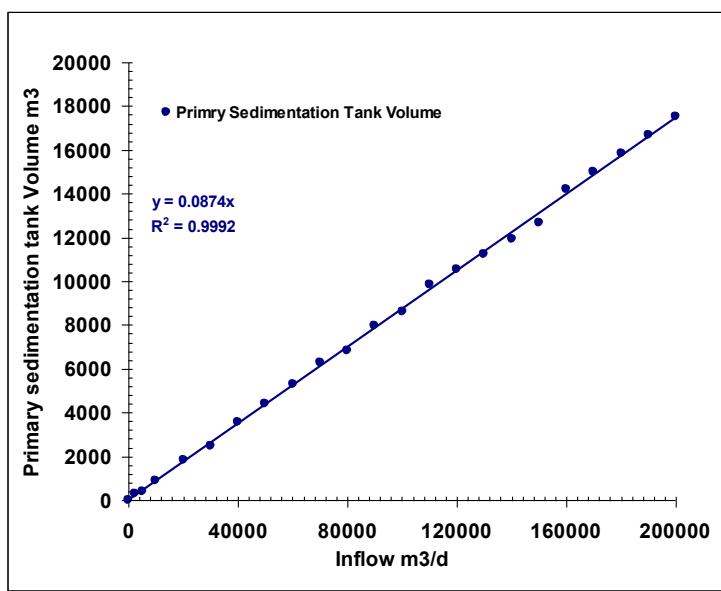

Figure (4): Primary Sedimentation Tank Regression Analysis

\subsubsection{Volume of Aeration Basins Models}

Table (4):Aeration Basin Models(WS From AB)

\begin{tabular}{|c|c|c|c|c|c|}
\hline \multirow[b]{2}{*}{$\mathrm{TSS}_{\text {inf }} \mathrm{mg} / \mathrm{l}$} & \multirow[b]{2}{*}{ BOD $_{\text {inf }} \mathrm{mg} / \mathrm{l}$} & \multicolumn{4}{|l|}{ Models } \\
\hline & & With PS & $\mathbf{R}^{2}$ & Without PS & $\mathbf{R}^{2}$ \\
\hline 150 & 150 & $\mathrm{y}=0.1338 X$ & 0.9997 & $y=0.1861 X$ & 0.9998 \\
\hline 200 & 200 & $y=0.18 X$ & 0.9997 & $y=0.2505 x$ & 0.9998 \\
\hline 250 & 250 & $y=0.2262 X$ & 0.9998 & $\mathrm{y}=0.3138 X$ & 0.9998 \\
\hline 300 & 300 & $y=0.2726 X$ & 0.9994 & $y=0.3778 X$ & 0.9974 \\
\hline 350 & 350 & $\mathrm{y}=0.3194 X$ & 0.9998 & $\mathrm{y}=0.3781 X$ & 0.9998 \\
\hline 400 & 400 & $y=0.3658 X$ & 0.9998 & $y=0.506 X$ & 0.9998 \\
\hline
\end{tabular}




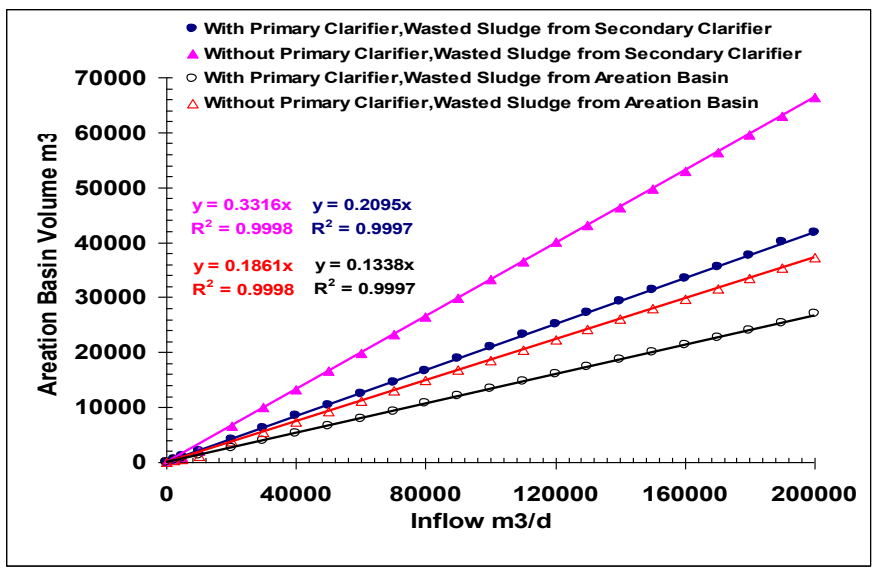

Figure (5): Aeration Basin Volume Data Fit $\left(\mathrm{TSS}_{\text {inf }}=150\right.$, BOD $\left._{\text {inf }}=150\right) \mathrm{mg} / \mathrm{l}$

\subsubsection{Volume of Secondary clarifier Models}

Table (5) Secondary clarifier Models (WS From AB)

\begin{tabular}{|c|c|c|c|c|c|}
\hline \multirow[b]{2}{*}{$\mathrm{TSS}_{\text {inf }} \mathrm{mg} / \mathrm{l}$} & \multirow[b]{2}{*}{$\mathrm{BOD}_{5 \inf } \mathrm{mg} / \mathrm{l}$} & \multicolumn{4}{|l|}{ Models } \\
\hline & & With PS & $\mathrm{R}^{2}$ & Without PS & $\mathrm{R}^{2}$ \\
\hline 150 & 150 & $y=0.2566 X$ & 0.9998 & $y=0.3067$ & 0.9998 \\
\hline 200 & 200 & $\mathrm{y}=0.3008 \mathrm{X}$ & 0.9998 & $y=0.3675 X$ & 0.9998 \\
\hline 250 & 250 & $\mathrm{y}=0.3448$ & 0.9998 & $y=0.4276$ & 0.9985 \\
\hline 300 & 300 & $\mathrm{y}=0.3888 \mathrm{X}$ & 0.9998 & $y=0.4876$ & 0.9973 \\
\hline 350 & 350 & $y=0.4328 X$ & 0.9998 & $\mathrm{y}=0.488$ & 0.9997 \\
\hline 400 & 400 & $y=0.4764 X$ & 0.9998 & $y=0.6075$ & 0.9997 \\
\hline
\end{tabular}

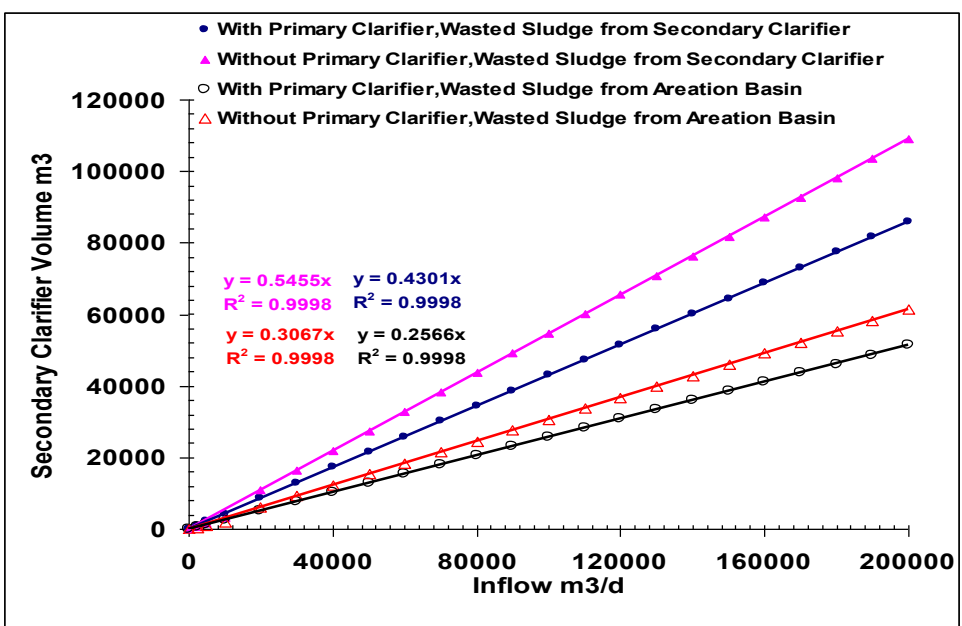

Figure (6):Final Clarifier Volume Data Fit $\left(\mathrm{TSS}_{\mathrm{inf}}=150, \mathrm{BOD}_{5 \mathrm{inf}}=150\right) \mathrm{mg} / \mathrm{l}$ 


\subsubsection{Volume of Gravity thickener Models}

Table (6) Gravity thickener Models (WS From AB)

\begin{tabular}{|c|c|c|c|c|c|c|}
\hline \multirow[b]{2}{*}{ TSS $_{\text {inf }} \mathbf{m g} / \mathbf{l}$} & \multirow{2}{*}{\multicolumn{2}{|c|}{ BOD $_{5 \text { inf }} \mathrm{mg} / \mathrm{l}$}} & \multicolumn{4}{|l|}{ Models } \\
\hline & & & With PS & $\mathbf{R}^{2}$ & Without PS & $\mathbf{R}^{2}$ \\
\hline 150 & 150 & & $y=0.0104 X$ & 0.9986 & $\mathrm{y}=0.0033 X$ & 0.9981 \\
\hline 200 & 200 & & $y=0.0147 X$ & 0.9995 & $\mathrm{y}=0.0053 \mathrm{X}$ & 0.9986 \\
\hline 250 & 250 & & $y=0.0191 X$ & 0.9996 & $\mathrm{y}=0.0074 X$ & 0.9981 \\
\hline 300 & 300 & & $\mathrm{y}=0.0235 \mathrm{X}$ & 0.9994 & $\mathrm{y}=0.0094 X$ & 0.9977 \\
\hline 350 & 350 & & $y=0.0278 X$ & 0.9996 & $\mathrm{y}=0.0095 \mathrm{X}$ & 0.9993 \\
\hline 400 & 400 & & $\mathrm{y}=0.0322 \mathrm{X}$ & 0.9997 & $\mathrm{y}=0.0136 X$ & 0.9993 \\
\hline & & 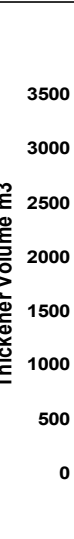 & $\begin{array}{ll}y=0.0107 x & y= \\
R^{2}=0.9996 & R^{2}= \\
y=0.0033 x & y= \\
R^{2}=0.9981 & R^{2}= \\
0 & 40000\end{array}$ & $\begin{array}{l}80000 \quad 120000 \\
\text { Inflow } \mathrm{m} 3 / \mathrm{d}\end{array}$ & $160000 \quad 200000$ & \\
\hline
\end{tabular}

Figure (7): Gravity Thickener Volume Data Fit $\left(\mathrm{TSS}_{\text {inf }}=150, \mathrm{BOD}_{5 \text { inf }}=150\right) \mathrm{mg} / 1$

\subsubsection{Volume of Anaerobic digester Models}

Table (7) Anaerobic Digester Models (WS From AB)

\begin{tabular}{|c|c|c|c|c|c|}
\hline \multirow[b]{2}{*}{ TSS $_{\text {inf }} \mathbf{m g} / \mathbf{l}$} & \multirow[b]{2}{*}{ BOD $_{5 \text { inf }} \mathrm{mg} / \mathrm{l}$} & \multicolumn{4}{|l|}{ Models } \\
\hline & & With PS & $\mathbf{R}^{2}$ & Without PS & $\mathbf{R}^{2}$ \\
\hline 150 & 150 & $y=0.0894 X$ & 0.9948 & $y=0.0613 X$ & 0.9927 \\
\hline 200 & 200 & $y=0.0894 X$ & 0.9950 & $y=0.0613 X$ & 0.9927 \\
\hline 250 & 250 & $y=0.1067 X$ & 0.9995 & $y=0.0414 X$ & 0.996 \\
\hline 300 & 300 & $y=0.1313 x$ & 0.9998 & $y=0.0531 X$ & 0.9987 \\
\hline 350 & 350 & $y=0.1562 X$ & 0.9998 & $y=0.0531 X$ & 0.9972 \\
\hline 400 & 400 & $y=0.1806 X$ & 0.9998 & $y=0.0757 X$ & 0.9991 \\
\hline
\end{tabular}




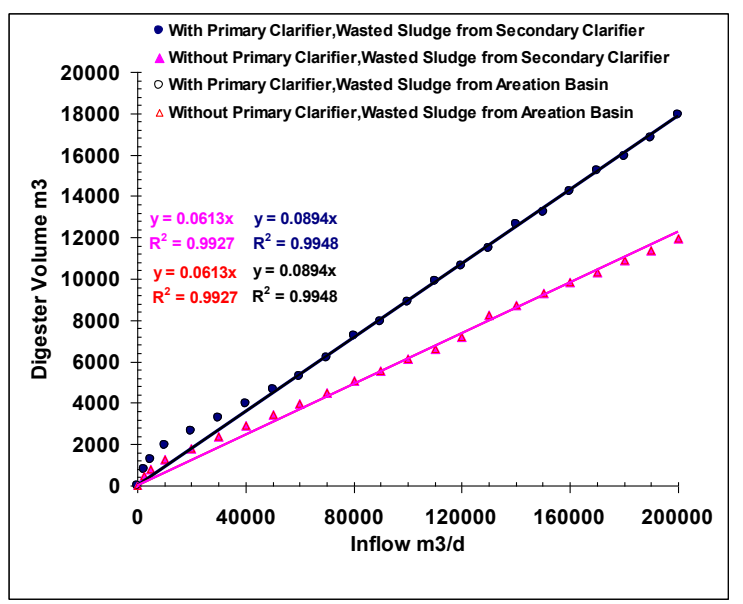

Figure (8): Anaerobic Digester Volume Data Fit $\left(\right.$ TSS $_{\text {inf }}=150$, BOD $\left._{5 i n f}=150\right) \mathrm{mg} / \mathrm{l}$

\subsubsection{Volume of Drying bed Models}

Table (8) Drying Bed Models (WS From AB)

\begin{tabular}{|c|c|c|c|c|c|}
\hline \multirow[b]{2}{*}{$\mathrm{TSS}_{\text {inf }} \mathrm{mg} / \mathrm{l}$} & \multirow[b]{2}{*}{ BOD $_{5 \text { inf }} \mathrm{mg} / \mathrm{l}$} & \multicolumn{4}{|l|}{ Models } \\
\hline & & With PS & $\mathbf{R}^{2}$ & Without PS & $\mathbf{R}^{2}$ \\
\hline 150 & 150 & $0.0007 \mathrm{X}$ & 0.9998 & $\mathrm{y}=0.0002 \mathrm{X}$ & 0.9998 \\
\hline 200 & 200 & $y=0.001 x$ & 0.9998 & $\mathrm{y}=0.0003 \mathrm{X}$ & 0.9998 \\
\hline 250 & 250 & $y=0.0013 X$ & 0.9998 & $\mathrm{y}=0.0004 \mathrm{X}$ & 0.9989 \\
\hline 300 & 300 & $y=0.0016 X$ & 0.9998 & $y=0.0006 X$ & 0.9982 \\
\hline 350 & 350 & $\mathrm{y}=0.0019 X$ & 0.9998 & $\mathrm{y}=0.0006 \mathrm{X}$ & 0.9998 \\
\hline 400 & 400 & $\mathrm{y}=0.0022 \mathrm{X}$ & 0.9998 & $\mathrm{y}=0.0008 \mathrm{X}$ & 0.9998 \\
\hline
\end{tabular}

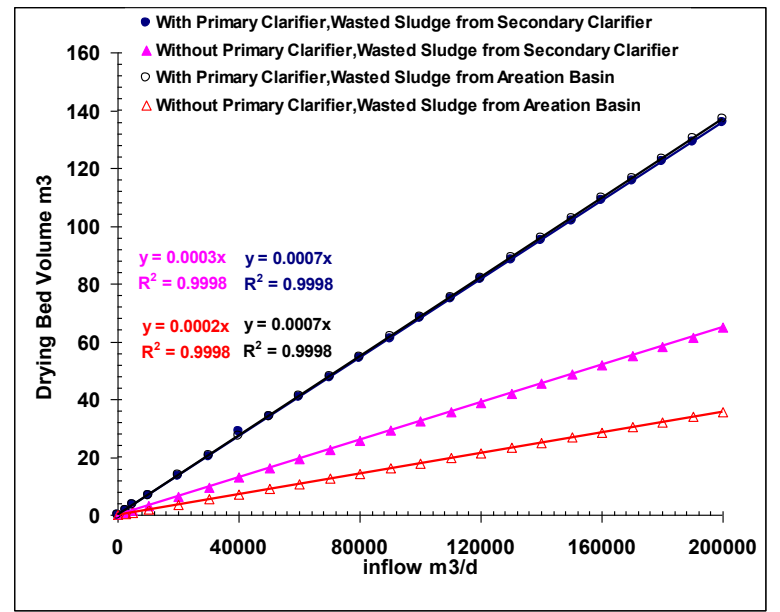

Figure (9): Drying Beds Volume Data Fit(TSS ${ }_{\text {inf }}=150$, BOD $\left._{\text {sinf }}=150\right) \mathrm{mg} / \mathrm{l}$ 


\subsubsection{Cost Estimation models}

Table (9): Cost Analysis Models

\begin{tabular}{|l|l|l|l|}
\hline $\begin{array}{l}\mathbf{T S S}_{\text {inf }} \\
\mathbf{m g} / \mathbf{l}\end{array}$ & $\begin{array}{l}\mathbf{B O D}_{\mathbf{5 i n f}} \\
\mathbf{m g} / \mathbf{l}\end{array}$ & Equation & $\mathbf{R}^{\mathbf{2}}$ \\
\hline 150 & 150 & $\mathrm{y}=3 * 10-24 \mathrm{X} 5-2 * 10-18 \mathrm{X} 4+4 * 10-13 \mathrm{X} 3-3 * 10-8 \mathrm{X} 2+0.0015 \mathrm{X}+81.075$ & 0.9591 \\
\hline 200 & 200 & $\mathrm{y}=10-25 \mathrm{X} 5-2 * 10-19 \mathrm{X} 4+9 * 10-14 \mathrm{X} 3-10-8 \mathrm{X} 2+0.0009 \mathrm{X}+81.069$ & 0.9017 \\
\hline 250 & 250 & $\mathrm{y}=3 * 10-25 \mathrm{X} 5-3 * 10-19 \mathrm{X} 4+10-13 \mathrm{X} 3-2 * 10-8 \mathrm{X} 2+0.0011 \mathrm{X}+75.141$ & 0.9006 \\
\hline 300 & 300 & $\mathrm{y}=5 * 10-25 \mathrm{X} 5-4 * 10-19 \mathrm{X} 4+9 * 10-14 \mathrm{X} 3-10-8 \mathrm{X} 2+0.0007 \mathrm{X}+85.808$ & 0.9064 \\
\hline 350 & 350 & $\mathrm{y}=-10-24 \mathrm{X} 5+6 * 10-19 \mathrm{X} 4-10-13 \mathrm{X} 3+7 * 10-9 \mathrm{X} 2+4 * 10-5 \mathrm{X}+91.044$ & 0.9622 \\
\hline 400 & 400 & $\mathrm{y}=2 * 10-24 \mathrm{X} 5-10-18 \mathrm{X} 4+3 * 10-13 \mathrm{X} 3-3 * 10-8 \mathrm{X} 2+0.0013 \mathrm{X}+79.553$ & 0.9747 \\
\hline
\end{tabular}

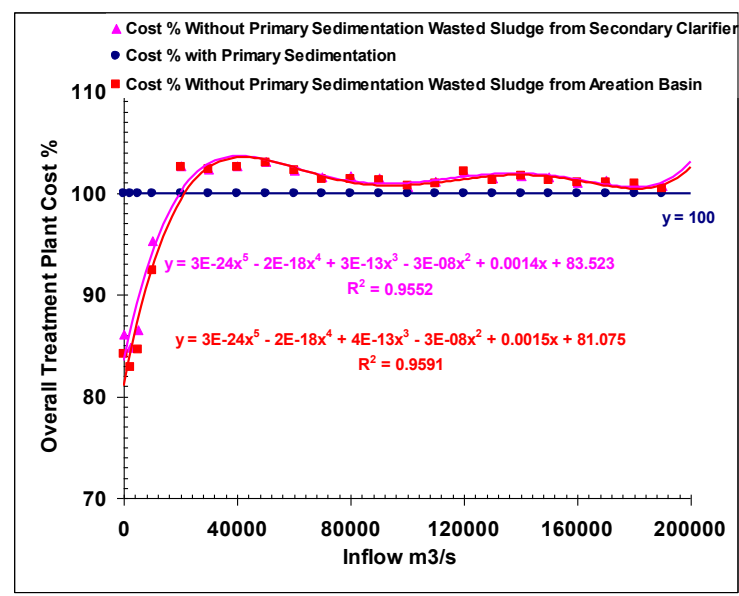

Figure (10): Cost Analysis of WWTP $\left(\mathrm{TSS}_{\mathrm{inf}}=150, \mathrm{BOD}_{5 \mathrm{inf}}=150\right) \mathrm{mg} / \mathrm{l}$

\section{Conclusions and Recommendations:}

The present study has come out with the following conclusions:

1. It is more engineering convenient, much faster and accurate to builda computer programsoftware forwastewater treatment plantdesign.

2. Generally an increments about $(52-170) \%$ for aeration basins volume and ( $58-185) \%$ for secondary sedimentation tanks were observed in the present study.

3. Approximately gravity thickener volume is decreased by about $(29-42) \%$, anaerobic digester volume is decreased by $(38-52) \%$ and drying beds is decreased by $(29-38) \%$ if the design disregarded the presence of primary sedimentation in the present study.

4. The analysis showed that the usage of primary sedimentation tanks on a wastewater treatment plant is more economic when the influent is above $(36,708.33) \mathrm{m} / \mathrm{d}$ when the wasted sludge from aeration basin, and $(24,833.33) \mathrm{m} / \mathrm{d}$ if the wasted sludge from secondary clarifier.

The effect of altering in temperature, $\mathrm{pH}$. Value and the presence of heavy metals in the effluent in the dimensional design of the treatment plant are recommended for practical future researches. 


\section{References}

[1] Izrail S. T. and P. K. Mathai, 2006, " Wastewater Sludge Processing ", John Wiley \& Sons, Inc. , New Jersey, USA.

[2] E.P.A., 2003," Biosolids Technology Fact Sheet. Gravity Thickening", Municipal TechnologyBranch. E.P.A. EPA 832-F-03-022, Washington D.C.

[3] Frank R. S., 2004 “Environmental engineer's mathematics handbook”, CRC Press LLC, USA.

[4]B. P and J. Oleszkiewicz, 2006, "Impact of Sludge Thickening on Energy Recovery fromAnaerobic Digestion",Technical Paper, Department of Civil Engineering, University of Manitoba.

[5] AL- Turaihy, T.A, 1993 " Factors Affecting the Choice of Sewage Treatment Methods"., MSc. thesis, College of Engineering, Department of Civil Engineering, Baghdad university.

[6] Ujang, Z.andSairan, F.2006 " How to use wastewater treatment plant design advisor program" ,Technical paper, University of technology, College of civil engineering, 81310 Skudai Johor, Malaysia university, E-mail: zaini@utm.my, fadzlin@utm.my.

[7] E. C. C. Ferreira, 2005"Biological Process Optimal Design in a Wastewater Treatment Plant ", Technical paper, College of engineering, University of Minho, Brazil.

[8] Xiaoyi Zhang, 2005 "Estimating Peaking Factors with Poisson Rectangular Pulse Model and Extreme Value Theory" Master of Science Thesis, University of Cincinnati ,USA.

[9] Arcadio P. S. S., 2003 "Physical-Chemical treatment of water and wastewater",CRC press LLC,USA.

[10] Donald. L. B. et. al., 2004 "Domestic Wastewater Treatment"Unified Facilities Criteria UFC3-24009A 16Department of the US army and the air force and Design Guide.

[11] Nikoletta K. and DespoF., 2004 "Urban Wastewater Treatment Technologies Part I" Report, Meda Water, Europe.

[12] WEF and American Society of Civil Engineers, 2008, "Operation of municipal wastewater treatment plants ", $6^{\text {th }}$ edition., Vol. 1, McGraw Hill companies, USA.

[13] Qasim, S. (1999). "Wastewater Treatment Plants". New York: Routledge, https://doi.org/10.1201/9780203734209

[14] Peavy,Howard S., et al. "Environmental engineering". McGraw-Hill, 1987

[15] C. C. Lee and Shun Dar Lin, 2007 " Hand book of environmental engineering calculation ", $2^{\text {nd }}$ edition, McGraw-Hill companies, USA. 